\title{
Guido Thomaz Marlière, o "semeador" de cidades na Zona da Mata Mineirai
}

\section{Ítalo Itamar Caixeiro Stephan}

Arquiteto, professor doutor do Departamento de Arquitetura e Urbanismo da Universidade Federal de Viçosa, Universidade Federal de Viçosa, Centro de Ciências Exatas e Tecnológicas, Departamento de Arquitetura e Urbanismo, Campus UFV CEP 36570.000, Viçosa, MG, stephan@ufv.br

\section{Josarlete Magalhães Soares}

Arquiteta e urbanista, professora mestre do Departamento de Arquitetura e Urbanismo da Universidade Federal de Viçosa, Universidade Federal de Viçosa, Centro de Ciências Exatas e Tecnológicas, Departamento de Arquitetura e Urbanismo, Campus UFV, CEP 36570.000, Viçosa, MG, josarlete.soares@ufv.br

\section{Isadora Maria Floriano Ribeiro}

Graduanda do curso de Arquitetura e Urbanismo da Universidade Federal de Viçosa, Rua José Braz da Costa Val, 45/303, Centro, Viçosa, MG, (31) 9272-8135, isadora.ribeiro@ufv.br

\section{Resumo}

No início do século XIX, com a expansão do povoamento em Minas Gerais, o Governo Português iniciou um processo de ocupação sistematizada das áreas de floresta então existentes na capitania. Foi dentro desse contexto que o militar Guido Thomaz Marlière foi enviado para Minas. Este artigo discorre sobre a influência de Marlière na formação de diversos núcleos urbanos na região da atual Zona da Mata Mineira. Mais especificamente, apresenta as principais ações realizadas em alguns desses núcleos, discutindo até que ponto o militar ultrapassou seu papel de pacificador de índios e se valeu de sua autoridade para fundar novos povoados.

Palavras-chave: formação de núcleos urbanos, Guido Thomaz Marlière, Zona da Mata Mineira.

i Este artigo apresenta parte dos resultados alcançados no âmbito de uma pesquisa financiada pelo CNPq. processo de formação de cidades no território mineiro vincula-se, historicamente, à descoberta do ouro nas últimas décadas do século XVII. A forma de extração do metal possibilitou o aparecimento de aglomerações humanas relativamente densas e a conseqüente formação de diversos núcleos urbanos. A cidade mineradora foi um fenômeno precoce e inédito no contexto da colonização, fixando-se antes mesmo que os mecanismos para o seu abastecimento fossem estruturados de forma eficiente. No entanto, diversas regiões do atual estado de Minas Gerais, onde não foram encontrados metais preciosos em quantidade significativa, acabaram sendo ocupadas de forma mais lenta ao longo dos séculos XVIII e XIX, como resultado de processos paralelos e posteriores ao momento de maior efervescência da atividade de extração mineral.

O processo de povoamento e de formação das cidades na atual região da Zona da Mata mineira (Figura 1) se relaciona, em grande parte, a esses processos paralelos e posteriores, se estendendo ao longo dos séculos XVIII e XIX e se revestindo de uma série de particularidades. Durante o período colonial, a imagem construída sobre a região, e reproduzida por muitos historiadores, era a de uma "área proibida" à ocupação: 
A região que até o presente conserva o nome de Matta, como já se disse, além dos aldeamentos do Pomba e do Presídio de S. João Baptista, até os annos de 1784 nenhuma diligência para seu aproveitamento mereceram por parte do governo.

A mineração, que tudo determinava, assim como deu azo a dilatar-se o povoado aos mais remotos sertões, por onde appareciam indícios de ouro, assim também foi causa que outras regiões ficassem intactas e até desconhecidas em vizinhança, às vezes, das mais antigas povoações.

Com as mattas de Leste succedeu também que, por não darem ouro, foram rigorosamente conservadas, sendo-Ihes impedido o acesso, como barreira contra os extravios, e por isso se chamavam áreas prohibidas. (VASCONCELLOS, 1974: 274)

De fato, enquanto foi vigorosa a mineração nas áreas centrais, a Coroa procurou manter o isolamento e o despovoamento dos territórios a leste da capitania como forma de evitar a proliferação de rotas que permitissem o extravio dos quintos reais. Embora a efetividade das medidas proibitivas possa ser questionada (CARNEIRO, 2008: 72-82), a densa floresta que cobria a região, onde se refugiaram diversas nações indígenas, configurou-se como uma barreira natural ao povoamento contínuo. Desse modo, o processo de ocupação da porção sudeste de Minas Gerais se intensificou à medida que os rendimentos das lavras minerais começaram a decrescer e a agricultura foi ganhando maior importância relativa dentro das atividades econômicas mineiras.

Numa tentativa de sistematizar tal processo, Giovanini (2006) identifica duas gerações de ocupação. A primeira, durante o século XVIII, teve como componentes duas frentes distintas: uma ao longo do Caminho Novo' ${ }^{1}$ ainda na primeira metade do século, e a outra desencadeada pelas migrações oriundas da região central da capitania, já na segunda metade dos setecentos, como consequência da estagnação da atividade mineradora. Tais migrações foram responsáveis pela implantação de propriedades de subsistência e pequenos núcleos voltados para o auto-sustento polarizados por Mariana e Vila Rica (atual cidade de Ouro Preto). A segunda geração partiu do sul da Mata, com a expansão da lavoura de café a partir do Vale do Paraíba fluminense, tendo relevância destacada principalmente a partir de meados do século XIX²

No entanto, permeando esses dois momentos, ocorreu gradativamente uma alteração de postura da Coroa portuguesa frente à ocupação do leste da capitania de Minas Gerais (SOARES, 2009: 61-68). A queda dos rendimentos da mineração levou a uma crescente procura por alternativas de dinamização da economia colonial. Dentro desse contexto, nas primeiras décadas do século XIX, o território que hoje constituiu a Zona da Mata transformou-se numa região de grande incentivo ao povoamento e à exploração de suas potencialidades econômicas, sobretudo no que diz respeito a sua incorporação à economia agrícola mineira. Para tanto, mereceu especial atenção por parte dos governos da capitania e do Império (português e depois brasileiro) a questão do contato das novas frentes de povoamento com a população indígena ainda habitante nas florestas a leste do território mineiro.

\section{A política de pacificação indígena nas primeiras décadas do século XIX}

Com a transferência da sede do governo português para a América, em 1808, o Brasil sofreu uma série de transformações em sua organização políticoadministrativa. Ao longo de todo o período de permanência da Corte no Rio de Janeiro - entre 1808 e 1821 -, o território brasileiro foi acometido por um amplo processo de abertura política e econômica, acompanhada de diversas tentativas de dinamização dos mais diversos ramos produtivos (HOLANDA, 1965: 9-39).

As primeiras ações de contato oficial com a população indígena que povoava as regiões leste e sudeste da capitania de Minas Gerais ocorreram ainda ao longo da segunda metade do século XVIII e corresponderam à aplicação da legislação indigenista do reino português no interior do território mineiro, sobretudo a aplicação do Diretório Indígena de 1757. Implantado durante a administração do Marquês de Pombal - primeiro ministro do governo português entre 1750 e 1777 - o Diretório tinha por objetivo normatizar as aldeias civis e regulamentar a liberdade indígena na região amazônica, promovendo a inserção dos nativos na sociedade colonial através de sua instrução na língua portuguesa, nas atividades econômicas e na estrutura social do colonizador. 
3 No entanto, mesmo após sua revogação, tal documento continuou influenciando as ações de contato com os nativos e os rumos da política indigenista no território hoje brasileiro.

4 Criadas a partir de 1808 , as Divisões Militares correspondiam a circunscrições territoriais onde atuava um corpo de tropa vinculado ao exército. Foram implantadas com o objetivo de promover o primeiro contato com as populações nativas e também proteger a frente de povoamento pioneiro de possíveis ataques indígenas. Em Minas Gerais, foram criadas sete Divisões de forma a cobrir as regiões de floresta a leste da capitania - aproximadamente os vales dos rios Doce, Jequitinhonha e Mucuri (ESPÍNDOLA, 2005: 105-244).

5 Após os anos de atuação de Marlière, a continuidade do processo de pacificação indígena no território mineiro ocorreu principalmente devido às ações empreendidas pela Igreja Católica, com o envio e fixação de padres capuchinhos nas regiões ainda habitadas pelos nativos e a difusão da catequese (CUNHA, 1992).
Estendido para toda a América Portuguesa no ano de 1758, o Diretório consolidou-se como a principal orientação para a política indigenista e regulou as ações colonizadoras dirigidas aos índios até ser abolido, em 179833 (PAIVA, 2009: 34).

Com o objetivo de promover o aproveitamento econômico e o povoamento regular das regiões de floresta ocupadas pelas populações nativas, a administração de Dom João VI promoveu um revigoramento da política indigenista então implantada na América portuguesa. Em Minas Gerais, o território que hoje constitui a Zona da Mata foi alvo direto da nova política. Foi em meio a esse contexto que, em 1813, chegou à região do Presídio de São João Batista - atual município de Visconde do Rio Branco (BARBOSA, 1995: 370) - o alferes Guido Thomaz Marlière, enviado para apaziguar querelas territoriais entre os índios e os novos colonos. Militar nascido na França, Marlière foi admitido no exército português em 1807 e veio para o Brasil em 1808, junto com a comitiva da Corte portuguesa. Ainda em 1813, foi designado "Diretor de Índios da Freguesia de São Manoel do Pomba, de São João Batista e aldeias anexas". O sucesso das ações de Marlière possibilitou o aumento e a extensão gradativa de seus poderes, o que levou a sua nomeação como Inspetor Geral de todas as Divisões Militares ${ }^{4}$ de Minas Gerais em 1820. Nesse cargo permaneceu até 1829, quando foi afastado já com sessenta anos de idade (JOSÉ, 1958; ESPÍNDOLA, 2005: 176-179, 214-220).

A política de pacificação indígena alcançou seus maiores resultados sobretudo nos anos de atuação de Marlière e principalmente na região onde ele desenvolveu a maior parte de seu trabalho: a porção central do que hoje conhecemos como Zona da Mata mineira. A partir de 1810, houve uma entrada expressiva de fazendeiros nas regiões de floresta, sobretudo no território da Zona da Mata (ESPÍNDOLA, 2005). Uma série de vantagens, como a concessão de privilégios, isenções fiscais e a doação de sesmarias, foi oferecida àqueles que se dispusessem a habitar os sertões. O povoamento regular era, assim, tanto uma consequência da política de pacificação como um meio para que o processo de ocupação territorial tivesse sua continuidade garantida.
Além do incentivo à ocupação territorial, outro aspecto fundamental da política indigenista foi o processo de sedentarização da população nativa em aldeamentos. O caráter nômade dessas populações fatalmente entrava em conflito com a expansão agropecuária em curso. Desse modo, para evitar os conflitos fazia-se necessário conformar os indígenas ao modo de vida luso-brasileiro. Nesse sentido, aldeias foram implantadas tendo a atividade agrícola como meio de sustento e a catequese como forma de tornar os índios mais dóceis e mais apegados aos centros onde existiam capelas e matrizes. Como consequência direta desse processo surgiram diversos núcleos urbanos no interior dos territórios de floresta de Minas Gerais ${ }^{5}$.

Desse modo, o trabalho de Marlière junto aos índios não se restringiu apenas à ampliação da fronteira agrícola de Minas Gerais, mas foi responsável pela formação de muitos dos núcleos urbanos primitivos de uma série de cidades da atual Zona da Mata mineira. Dentro desse contexto, o objetivo geral desse trabalho foi investigar o modo como se deu a atuação do então Diretor Geral de Índios, Guido Marlière, no território da Zona da Mata no que se refere especificamente ao processo de implantação de aldeamentos indígenas e as características que tais assentamentos assumiram do ponto de vista de sua primitiva morfologia urbana. Além disso, pretendeu-se identificar as atuais cidades da Zona da Mata cujos núcleos urbanos se formaram no contexto do processo de pacificação indígena, tendo sido implantados pela iniciativa direta de Marlière.

\section{Sobre Guido Marlière}

Guido Thomaz Marlière nasceu em Jarnage, no centro da França, em 1767. Pouco se tem conhecimento sobre sua vida na França. Aos 18 anos ingressou no exército que lutou na Revolução Francesa ao lado do Rei Luiz XVI. Fez campanhas na Inglaterra, Espanha e em Portugal, onde conheceu sua esposa, Maria Vitória. Foi através de sua família, e da estreita relação com a Corte Portuguesa, que Marlière foi contratado pelo Exército Português e veio, em 1808, para o Brasil. Em 1809, foi incorporado às tropas do Príncipe Regente, sob a patente de porta-estandarte de cavalaria, e, assim, começou sua trajetória na América portuguesa. Dois anos mais tarde, D. João 
VI concedeu a transferência do francês para Minas Gerais. Marlière e sua esposa mudam-se, então, para Vila Rica (atual Ouro Preto), e se estabelecem em terras doadas pela Coroa (AGUIAR, 2008: 7981 e 102).

Em virtude das Guerras Napoleônicas, a vigilância do Império português contra possíveis opositores e espiões se intensificou. Guido, devido a sua origem francesa, passou a ser alvo de desconfianças e acusações por parte dos portugueses. Assim, em 1811,

Recebidas as denúncias, o govêrno do PríncipeRegente, em aviso secretíssimo do Ministro Conde de Linhares, ordenou, em 4 de Julho do mesmo ano, ao Governador de Minas, Conde de Palma: "logo que receber este Aviso, o faça observar (observar Marlière) em todas as suas acções, e conhecer de todas as Pessoas, que com elle vivem, em que ele perceba que ha contra elle a menor suspeita, e que passado mez e meio de observação, e quando elle possa estar totalmente despercebido, e descuidado, V. Exa o faça prender tomando-Ihe todos os seus papéis, e correspondências e o mande remeter aqui, com toda a segurança o Intendente Geral da Policia. (JOSÉ, 1958: 26)

Após a prisão foram apreendidos 47 papéis do francês, porém, sua análise revelou que nenhuma acusação era procedente. Em 1813, depois de inocentado, Marlière retornou à Vila Rica e recuperou também seu posto. Ao retornar, foi desviado de suas funções e encarregado de uma missão, que, embora de abrangência local, investia-Ihes consideráveis poderes. Deveria comandar a pacificação entre os índios e os colonos portugueses na região do Presídio de São João Batista. Por esta razão, foi nomeado "Diretor Geral dos Índios da Freguezia de São Manoel do Pomba, de São João Baptista e Aldeias Anexas" (JOSÉ, 1958: 29 e 36).

Permaneceu no Presídio até 1816, quando foi promovido a Capitão do $4^{\circ}$ Regimento ao qual pertencia. Em função da eficiência com a qual realizava seu trabalho, passou a receber cargos de diretoria indígena cada vez mais elevados, tendo alcançado o posto de Diretor Geral dos Índios de Minas Gerais, em 1824. Marlière foi um dos colonizadores mais importantes da região, tendo tido influência nas bacias dos rios Jequitinhonha, Doce, Pomba e Paraíba do Sul.

A implantação de núcleos urbanos, escolas de primeiras letras, capelas e a abertura de estradas eram ações inseridas dentro do processo de fixação da população indígena. Conforme relatado pelos viajantes Spix e Martius (1961: 237), que estiveram na região dos aldeamentos por volta do ano de 1817, a principal dificuldade relacionada ao processo de sedentarização indígena era introduzi-los na agricultura, para que pudessem administrar a terra que thes era concedida. Cabia ao Diretor de Índios, no caso, Guido Marlière, evitar a usurpação das terras doadas aos nativos por parte dos novos colonos, além de garantir os direitos dos índios como cidadãos. Segundo os referidos viajantes, tal função foi desempenhada com grande eficiência pelo francês.

No período em que atuou como Diretor Geral de Índios, Marlière construiu uma fazenda, chamada Guido Wald (mata do Guido, em alemão), em um lugar conhecido como Serra da Onça, de onde comandou boa parte da região que atualmente constitui a Zona da Mata mineira. Em 1836, já velho e abatido, faleceu nessa fazenda, onde hoje está erguido um monumento em sua homenagem.

\section{Marlière e os núcleos urbanos da Zona da Mata Mineira}

As ações de Marlière abrangeram todo o leste de Minas Gerais. No que se refere especificamente à Zona da Mata, embora as referências encontradas nem sempre sejam muito precisas, foi possível verificar que algumas de suas cidades tiveram sua formação territorial estreitamente vinculada à atuação de Marlière, outras foram impactadas de forma indireta, tendo seu crescimento impulsionado a partir do processo mais amplo de pacificação da população indígena e de aumento demográfico da região.

A partir de um levantamento bibliográfico junto a fontes primárias e secundárias - sobretudo documentos transcritos pela Revista do Arquivo Público Mineiro - e também a partir de entrevistas com pessoas ligadas à história de cada cidade, foi possível elaborar um panorama sobre a atuação do militar na região. Vale destacar a enorme dificuldade 
Figura 1: Localização dos municípios da Zona da Mata que receberam influência de Guido Thomaz Marlière em sua formação territorial e urbana. Fonte: Adaptado de MINAS GERAIS, 2007. encontrada para obter registros escritos e mapas primitivos dos núcleos urbanos. Fato que aponta, em parte, a precariedade com que os processos de ocupação territorial se procediam no Brasil dos oitocentos e também a inexistência de uma cultura de identificação e preservação de documentos que testemunhem os processos de formação e crescimento dessas cidades.

Quando identificamos num mapa os municípios onde foram identificadas ações de Guido Marlière (FIG. 1), podemos perceber que, na Zona da Mata, a atuação do francês impactou principalmente os núcleos urbanos localizados em sua região central, onde originalmente foi instalada a Diretoria Geral dos Índios.

De forma a ilustrar o modo de atuação de Marlière junto aos núcleos urbanos da Mata mineira, apresentamos, na sequência, uma série de ações articuladas (e na maioria das vezes executadas) por ele relativamente a esses mesmos núcleos.
Argirita

O núcleo inicial de formação da cidade era denominado Rio Pardo. Em 1814, esse núcleo recebeu, às margens do rio de mesmo nome, o aldeamento de 500 índios Puris (ARAÚJO, 2004: 15).

\section{Cataguases}

Guido Thomaz Marlière, no momento em que abriu a estrada entre Minas e Campos dos Goytacazes, recebeu - do Sargento Henrique José de Azevedo - a doação de um terreno para a construção da capela do povoado de Porto dos Diamantes. Assim, em 26 de Maio de 1828, aceitando a doação de terras, mandou erigir, sob invocação de Santa Rita, a capela do futuro arraial.

O terreno se confrontava "ao nascente com o ribeirão chamado Meia Pataca; ao poente, com o rio Pomba, e ao nordeste com um pequeno córrego que deságua no Meia Pataca, e pelos fundos com

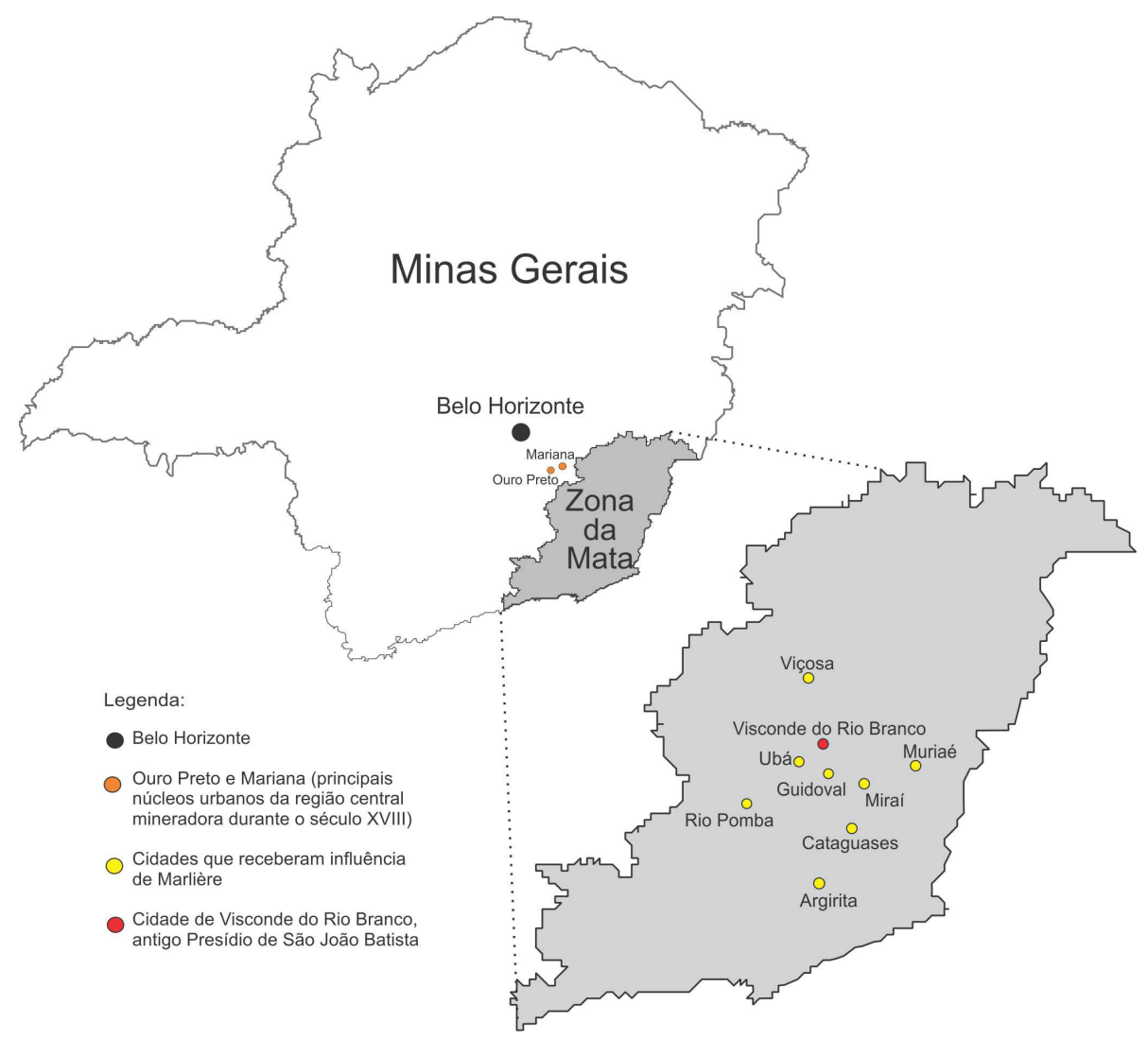


o doador" (SILVA, 1908: 162). A primeira atitude de Marlière foi demarcar o terreno com marcos de madeira para evitar conflitos com a população local. As ruas foram traçadas a uma distância de 50 passos de um a outro ângulo da capela. O local da praça central foi escolhido e estabelecido como espaço público, sendo proibida a construção de casas. Com relação aos lotes e afastamentos, Marlière:

Deixo os mais poderes e a recommendação ao sargento Henrique José de Azevedo para conceder terreno para casas e quintaes, na projecção delineada, deixando sete palmos de intervallo entre uma casa e outra, para serventias publicas e poder acudir a qualquer incêndio, na fôrma do retro citado Directorio para a creação de arraiaes em terras de índios. O Directorio não concede mais de 60 palmos de frente e cem de fundos para quintal (permitindo-o o terreno), para o reverendo capellão, commandante e pessoas graduadas, 50 ditos para os que são de classe média com 80 de fundos. 40 enfim para os mais habitantes e 70 de fundos. Nada de quintaes nas frentes, entremeados com as casas. (SILVA, 1908: 162)

Figura 2: Recorte de parte da área urbana da cidade de Cataguases com destaque para o traçado inicial implantado no momento da formação do arraial. Fonte: Elaboração a partir de base disponível em Google Earth, 2011.
Conforme pode ser observado, a atuação de Marliére no processo de assentamento do núcleo urbano inicial da cidade de Cataguases foi bastante ampla, incluindo não só a demarcação do local de implantação da capela e a abertura das primeiras ruas como determinando os padrões de tamanho e ocupação dos lotes do futuro arraial.

Conforme aponta Silva (1908:163), o traçado da cidade teve início, portanto, no Largo da Matriz de Santa Rita e no Largo do Rosário - atual Praça Rui Barbosa. Do Largo da Matriz até a margem direita do ribeirão Meia Pataca foi aberto o caminho do sobedesce, atual Rua Coronel Vieira. O conjunto formado pelo Largo da Matriz e a atual Praça Rui Barbosa também foi o ponto de partida para a definição de outros caminhos: Passa-cinco (rua alferes Henrique de Azevedo), Pomba (Rua Major Vieira), do Meio (Rua Rebelo Horta), do Cemitério (Rua Marechal Deodoro) e da Estação (Rua Coronel João Duarte). A malha de ruas retas e perpendiculares, com praças espaçosas, localizada na área relativamente plana entre os cursos do rio Pomba e dos ribeirões Meia Pataca e Lava-pés é a mesma configuração que pode ser observada hoje. Com o crescimento do núcleo urbano, as ruas passaram a acompanhar os terrenos planos ao longo dos trilhos da Estrada de Ferro Leopoldina, ou as curvas de nível das encostas dos morros. Ao longo do século XIX, não houve outro plano ou diretriz de expansão além das primeiras normas do Diretor de Índios e as próprias contingências topográficas (Figura 2).

Cerca de 20 anos após a implantação do arraial, a impressão do naturalista alemão Burmeister, que percorreu a região por volta do ano de 1851, nos

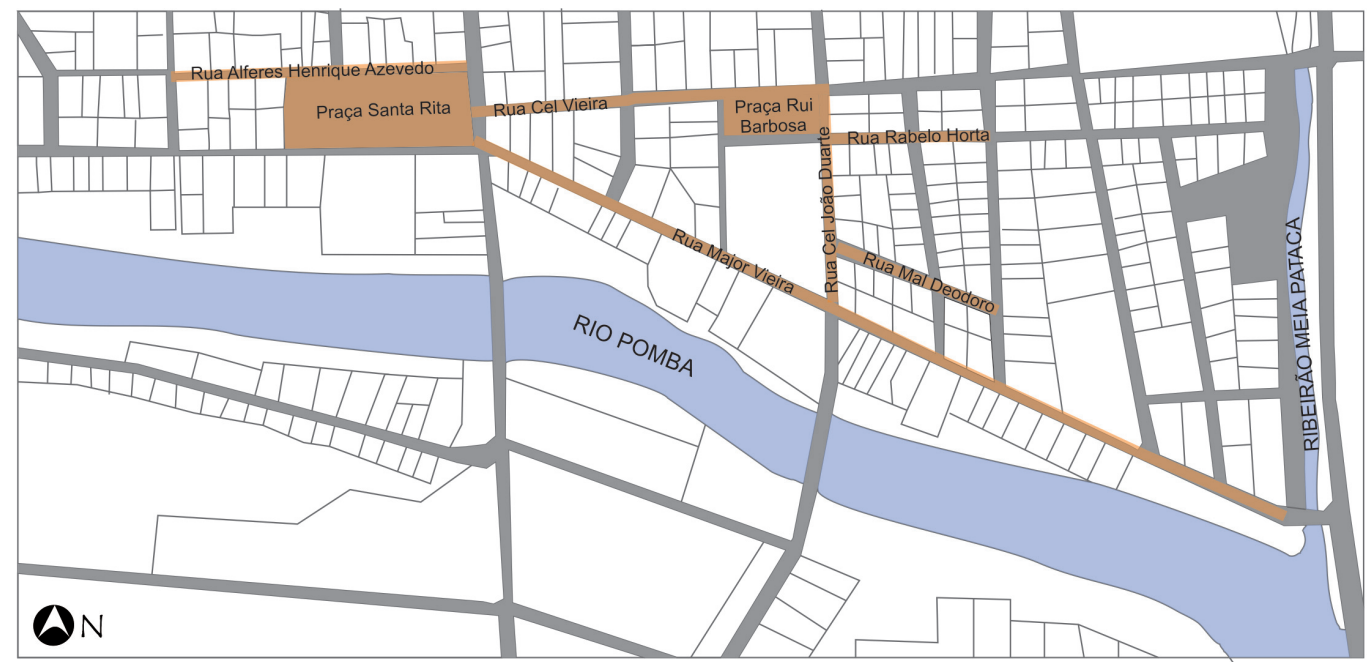


aponta a continuidade do crescimento do núcleo urbano:

A aldeia forma um retângulo em cujo meio se encontra a igreja, por onde passa a estrada que conduz até a ponte e às margens do rio Pomba. As casas eram todas de aspecto agradável e emolduradas por faixas brancas de cal. Havia, mais ou menos, umas 30, inclusive uma farmácia na grande praça onde estava a igreja. Esta última, que ainda não se encontrava concluída, parecia haver sido idealizada em grande estilo. (...) Nesta ocasião, estavam cobrindo as paredes do coro com barro e preparando os fundamentos da nave lateral, enquanto a central apresentava-se ainda descoberta e livre. O lugar revela certo movimento, e a estrada vinda do interior, atravessando o rio da Pomba e seguindo para Cantagalo e Nova Friburgo até o Rio de Janeiro, aumenta-Ihe ainda a importância. (BURMEISTER, 1980: 112)

\section{Guidoval}

A cidade recebeu seu nome em homenagem a Guido Thomaz Marlière, que constituiu sua fazenda nas proximidades do então arraial do Sapé (BARBOSA, 1980: 146). A fazenda, que era conhecida como Guido Wald, era um misto de residência, quartel e sede administrativa, onde Marlière empregava índios em afazeres agrícolas remunerados. Após sua morte, um monumento foi erigido em sua homenagem, com os dizeres:

À memória de Guido Tomás Marlière desbravador das selvas e civilizador dos índios, abrindo estradas e semeando núcleos de população, as Câmaras Municipais de Ubá, Cataguases, Rio Branco e Pomba fizeram erigir este monumento, símbolo da gratidão ao pioneiro de progresso de Minas. Inaugurado em 1928 (BARBOSA, 1995: 146).

Miraí

Os índios Puris, que habitavam a região da atual cidade de Miraí, foram aldeados pelo francês, que se tornou um dos primeiros benfeitores da localidade, conhecida como Brejo de Santo Antônio (JOSÉ, 1958: 198).

. Muriaé

A aldeia de São Paulo do Manuel-Burgo, atual Muriaé, surgiu com a divisão feita por Marlière dos distritos indígenas. O distrito dos índios Puris teve como sede o aldeamento implantado nesta localidade; os Coropós ficaram sediados em São Manuel do Pomba (atual Rio Pomba), e os Coroados em São João Batista do Presídio (atual Visconde do Rio Branco) (AGUIAR, 2008: 187).

O documento mais antigo referente a esse processo são os Atos de Medição, onde são estabelecidos os limites do novo povoado. Nos anos de 1814 e 1815, Marlière tomou as primeiras providências em relação à constituição do novo arraial: mandou construir um quartel, uma escola de primeiras letras e uma Igreja dedicada ao apóstolo São Paulo (JOSÉ, 1958: 187). O aldeamento, que tinha cerca de três léguas quadradas, surgiu oficialmente em 16 de agosto de 1819.

Segundo um dos oficiais encarregados da demarcação, o comandante Guido Marliére ordenou que

(...) medisse e demarcasse nove mil braças em quadra para este fim; principiando minha medição pela parte de cima em hum Rebeirão, por esta cauza, demos o nome de Divizorio; servindo as suas agoas de Lemite natural entre as porreçoens dos ditos Índios, e dos Portuguêzes que pelo fucturo vierem a povoar o Sertão. Alli, que se contão onze legoas medidas e demarcadas do Prezídio de S.m João Baptista ao dito Riberão Divizorio, voltemos para o rumo do Oeste para o Leste, pelo Rio do Robinson Cruzoé abaixo, e medimos nove Mil braças, ou tres Legoas, que findarão em hua grande varje de muitos tocoarussus, e cortada por hum valão ahode se acha hum Páo de Jacarandá preto ahi nassido, em que fizemos tres Cruzes a golpes de machado; Cujo sítio se acha vista de hua grande Pedra ao norte que representa hum Castello (hoje Pedra Santa Maria), servindo este modo o Rio de Robinon Cruzoé e parte do Muriahé, de limites ao Norte. - E voltanto para o Sul, fomos à Serra que divide as agoas do Pomba com o Muriahé no alto do qual se ade fincar hum Padrão Lavrado de quatro faces, que fique servindo de Limites entre as terras dos Puris, e o Sertão do Leste. E para concluir a quadra de Leste para o Oeste o dito Cap.am de Cavalaria de Linha e Derector Geral declarou que a dava por feito e acabada pois não avia feixo milhor do que o ponto mais elevado da mesma Serra. Nesta forma dei por feita e acabada a medição e demarcação das ditas 
6 Além da abertura das fronteiras para a expansão agrícola, a pacificação indígena também era parte de um projeto que pretendia fornecer a Minas Gerais uma alternativa fluvial de acesso ao mar através da navegação pelo leito do rio Doce. A Junta de Conquista e Civilização dos Indios e da Navegação do Rio Doce foi criada pela Coroa Portuguesa com o objetivo de viabilizar a consolidação de tal acesso (ESPÍNDOLA, 2005).

Figura 3: Mapa topográfico do povoamento da ex-Vila do Presídio - 1854. Fonte: PINTO, 1854. terras. - E para consta fizemos este Termo neste ja referido quartel por mim feito e sob escrivido, asim como todos àsima nomeados, aos tres de Setembro de mil oito sentos e dezanove, dia que findou a medição: -João do Monte da Fonsec -Alf.s Comm. te de $2^{a}$ Divizão - Lucio Pires - Joaquim Joze - Francisco de Paula SIlveira - Guido Ths Marlière, Director Geral" (MARGE, 2005: 5)

Conforme pode ser constato a partir desse documento, a preocupação em demarcar as terras indígenas e fixar os núcleos de povoamento era uma forma de evitar disputas territoriais entre os nativos que originalmente habitavam a região e os novos colonos que para lá migravam. Desse modo, ao evitar possíveis conflitos territoriais, o processo de aldeamento indígena tornou-se um mecanismo eficiente de abertura da floresta ao povoamento luso-brasileiro e ao aproveitamento econômico.

\section{Visconde do Rio Branco}

Nas primeiras décadas do século XIX, o povoado, que já existia desde 1787, passava por constantes conflitos entre índios Coroados e colonizadores. Marlière chegou a São João Batista do Presídio em fevereiro de 1813 e lá iniciou sua atuação junto aos indígenas. Passou quatro anos no arraial, estabelecendo ali a sede da direção indígena. Contribuiu significativamente para o desenvolvimento desse núcleo urbano.
Solicitou a construção de uma escola de primeiras letras à Junta de Conquista e Civilização dos Índios e Navegação do Rio Doce ${ }^{6}$, além de combater o consumo de aguardente entre os índios, o que os deixava mais agressivos (AGUIAR, 2008: 167). Com a ajuda do Padre. Francisco da Silva Campos e do Padre José Lopes Meireles, que continuaram com suas ações pacificadoras, a nascente localidade cresceu significativamente (JOSÉ, 1958: 191-192). No ano de 1824, Langsdorff, em sua passagem pela região, assim a descreveu:

O Presídio consiste em uma longa fileira de casas localizadas num vale, no sopé de alguns morros e de uma suave colina, sobre a qual está a capela de São João Batista. Ela foi construída, com a paróquia, há mais de 30 anos para a conversão dos índios. Nessa época, ninguém quis se estabelecer aqui, mas, há cerca de 10 anos, de repente, muitas pessoas, principalmente da região de São Miguel, depois de Catas Altas, mudaram-se para cá. Hoje essa freguesia, certamente bastante extensa e com muita área rural, já possui mais de 660 chaminés - o local tem 360 casas. A localidade tem mais de 800 almas, talvez mais, pois as famílias são muito numerosas. (LANGSDORFF, 1824 apud SILVA, 1997: 89)

Essa morfologia urbana caracterizada por uma longa fileira de casas, onde tem destaque apenas - local escolhido para a implantação da capela, pode ser identificada num mapa de 1854 (Figura 3).

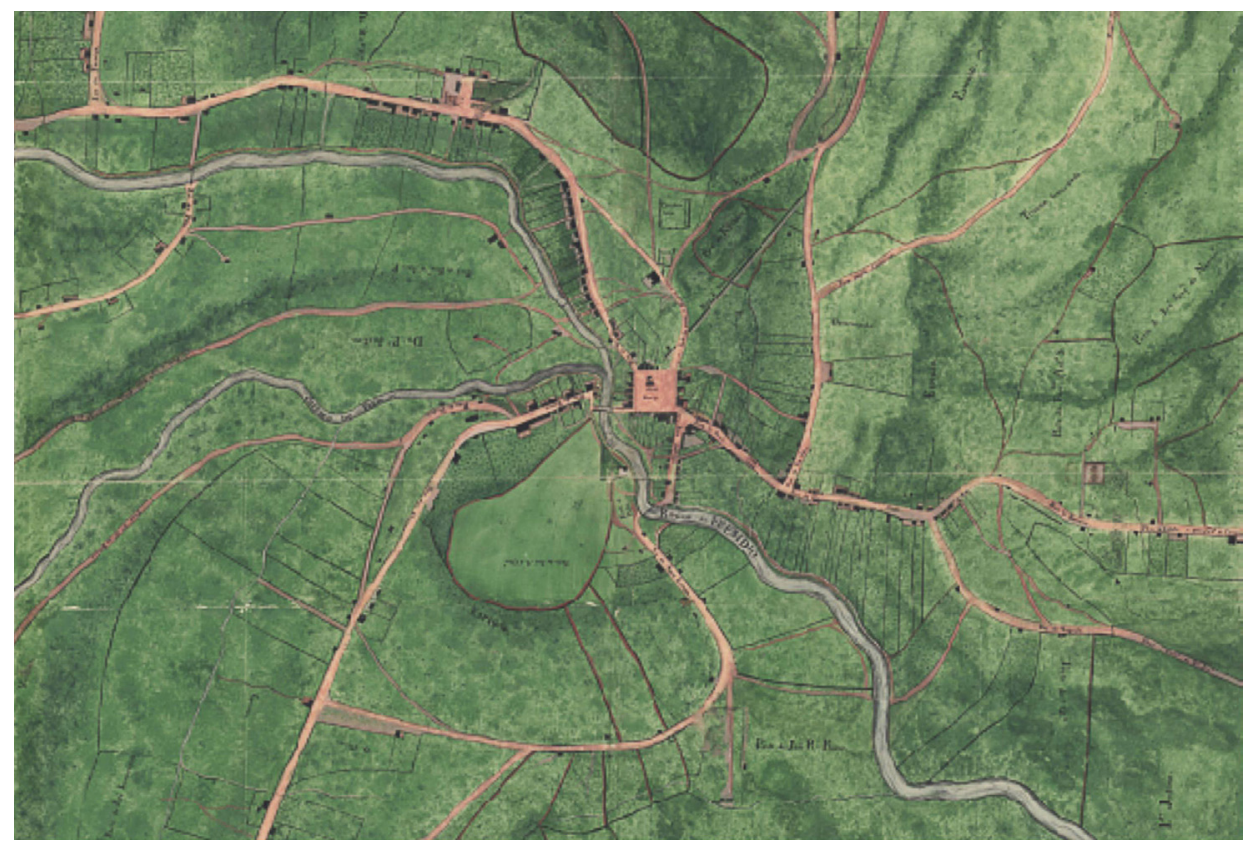




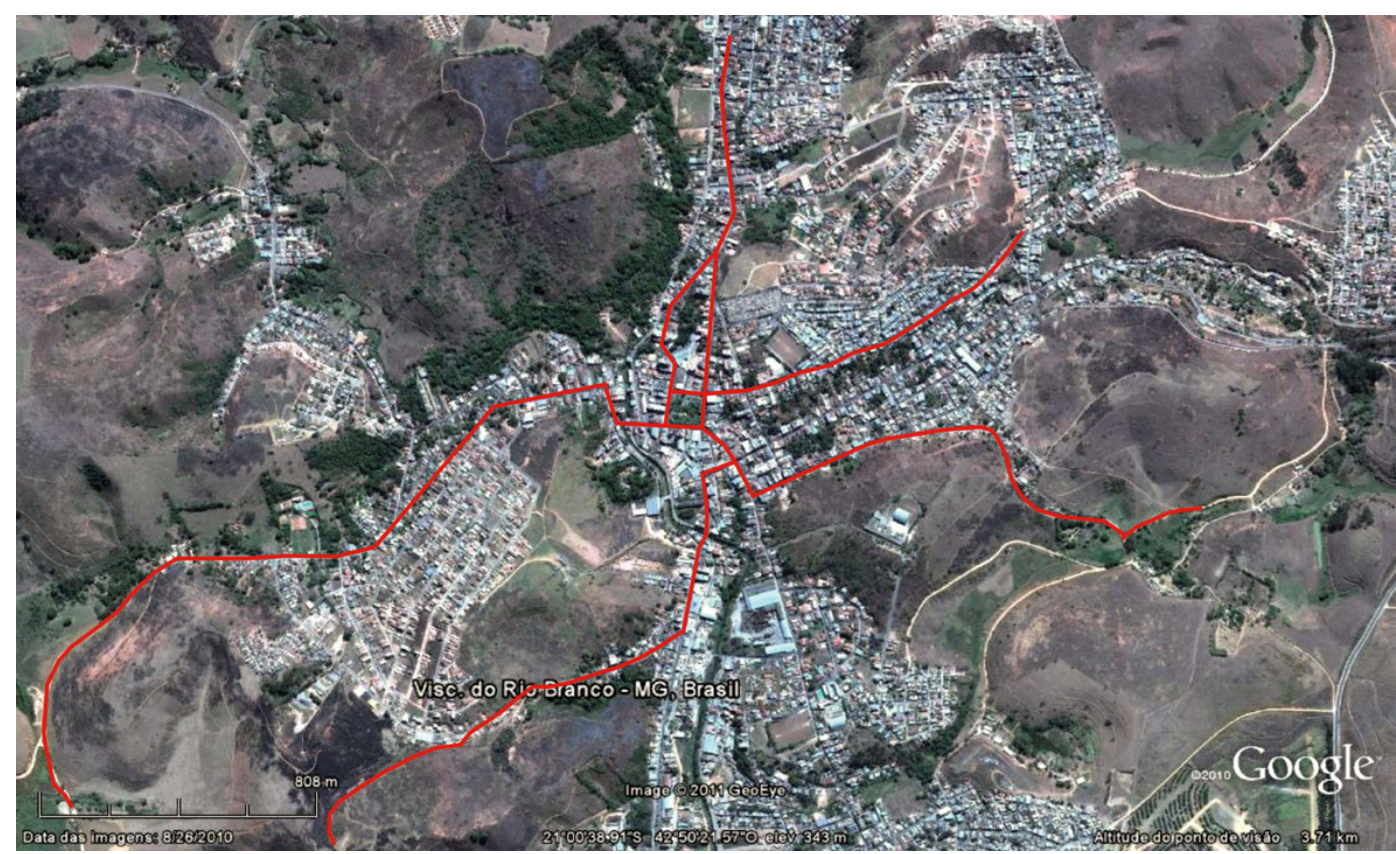

Figura 4 : Vista aérea da atual cidade de Visconde do Rio Branco com destaque para as vias originais implantadas na localidade. Fonte: Elaboração a partir de base disponível em Google Earth, 2011
Nele percebemos a configuração das ruas partindo dos vértices da praça central (um retângulo) e uma visível concentração de edificações nas proximidades dessa praça e na rua que acompanha o curso do rio. Quando esse mapa é comparado com uma imagem aérea atual da cidade, percebemos que o traçado urbano original ainda pode ser identificado. Observa-se que as vias principais de acesso à cidade e as de circulação dentro dela conservaram boa parte de sua configuração inicial (Figura 4).

\section{Rio Pomba}

Marlière, enquanto Diretor dos índios do Pomba, administrou a localidade e revezou sua sede de administração com São João Batista do Presídio. Os viajantes Langsdorff e Burmeister passaram pela região e nos deixaram registros bastante diferentes sobre o núcleo urbano. Em 1824, Langsdorff assim o descreveu:

A aldeia do Pomba ficou aquém de nossas expectativas. É o lugar mais miserável que já encontramos até hoje. A igreja é uma das mais antigas da região e agora está em franca decadência. Como todas as outras, ela é de pau-a-pique e fica numa praça aberta e livre. O lugar tem várias ruas, as casas são pequenas e térreas e, neste momento, estão quase todas abandonadas pelos seus habitantes, que estão todos em Descoberta Nova. Um padre tem, bem perto da aldeia, um moinho de canade-açúcar e uma venda. (LANGSDORFF, 1824 apud SILVA, 1997: 72)

Já em 1851, Burmeister nos apresenta o seguinte panorama:

... ao dobrar a estrada, que passava ao pé da colina, avistei uma grande cidade, com belas casas, caiadas de branco, e duas igrejas. Agradável surpresa! (...) Um grande quadrado no centro forma a praça principal, flaqueada por belas construções de dois andares. A leste vemos a matriz de Santo Antônio e, a norte, a Casa da Câmara com a prisão, um grande edifício de madeira, cujo estuque de barro já estava caindo em vários pontos. (...) No mercado havia ainda três casas comerciais, com mercadorias variadas, freqüentadas, nas horas da tarde, pelas senhoras que ali faziam suas compras, adquirindo fazendas e admirando as últimas criações da moda. Numa rua paralela à nossa, que saía da praça principal, vi uma farmácia e, na sala contígua, uma pequena biblioteca, a primeira que encontrei no interior do país. (BURMEISTER, 1980: 198) 
Essa diferença de impressão por parte dos dois viajantes provavelmente se relaciona ao tempo transcorrido entre as duas visitas. Burmeister passou pela vila quase trinta anos depois de Langsdorff. $\mathrm{Na}$ realidade, tal diferença de percepção só reforça o crescimento que o núcleo urbano alcançou a partir dos trabalhos de pacificação indígena empreendidos por Marlière.

\section{Viçosa}

A ocupação em terras viçosenses iniciado-se provavelmente a partir de meados do século XVIII, por exploradores de minérios e suas famílias. A intensificação da ocupação na localidade se deu com a doação de sesmarias a partir de 1781 (PREFEITURA..., 2010).

Segundo Langsdorff (1824 apud SILVA, 1997: 103), no início do séc. XIX, o povoado de Santa Rita apresentava uma capela dedicada à santa, que deu nome à localidade. No entanto, tal capela estava implantada em um terreno particular. Assim, a população local, que não tinha acesso direto as terras junto ao templo, começou a se estabelecer o mais próximo possível delas: do outro lado de um córrego distante dez minutos da capela.

Com a morte do proprietário, a população, com intervenção do bispo, pediu aos herdeiros a doação das terras da capela para constituição do patrimônio de Santa Rita. Foi a partir desse momento que o arraial iniciou seu crescimento junto ao referido templo. Embora não tenham sido encontradas referências sobre o traçado no novo arraial, Langsdorff aponta Marliére como o responsável pelo seu delineamento inicial: "A localização é muito boa, de forma que vai ser possível construir uma vila bonita e bem organizada, com ruas largas e praças abertas. 0 Sr. Guido Marlière, como líder dos índios a quem pertencia esta região foi incumbido de dirigir as obras." (LANGSDORF, 1824 apud SILVA, 1997: 104).

\section{. Ubá}

A pequena aldeia de Ubá recebeu, a pedido e Marlière, a licença para a construção da capela de São Januário de Ubá, anexa à Matriz de São João Batista do Presídio. Não constam relatos de visita do francês à localidade (CARNEIRO, 1990: 54).

\section{Considerações finais}

Conforme pudemos constatar ao longo deste trabalho, Guido Thomaz Marlière, além de reconhecido pacificador de índios, foi também agente importante na formação e crescimento de algumas das atuais cidades da Zona da Mata mineira.

Ao longo do relativamente curto período em que atuou no processo de aldeamento indígena - entre 1813 e 1829 - estabeleceu as fundações iniciais de diversos povoados. Sua atuação fundamentava-se na própria tradição católica portuguesa, em que a capela tornou-se um elemento fundamental de fixação humana. Ao longo de todo o período colonial e também no século XIX, a implantação das capelas e seus patrimônios foi responsável pelo surgimento de uma série de núcleos urbanos no interior do território hoje brasileiro (ver MARX, 1991 e MATA, 2002). Marlière utilizou-se desse artifício para promover a pacificação e sedentarização indígena. Era necessário fixar núcleos de referência para a população nativa, assim como a própria catequese era também uma forma de domesticação.

Nas localidades nas quais atuou, Malière também promoveu a construção de outros equipamentos, como escolas de primeiras letras, quartéis, hospedarias, o que inegavelmente estimulou o crescimento dessas povoações. Quanto às questões relativas ao traçado urbano, o caso de Cataguases é singular, uma vez que Marlière, além de determinar a implantação de alguns equipamentos, também estipulou regras sobre o parcelamento da terra, definiu afastamentos e usos do solo.

Em algumas publicações sobre a vida de Guido Marlière, comenta-se que ele, além de desbravador das selvas e civilizador dos índios, espalhou sementes de café na Zona da Mata e no Leste mineiro. Considerando o papel fundamental que desempenhou na formação de uma série de núcleos urbanos da região, pode-se dizer que o militar também semeou cidades. Essa faceta de sua obra ainda é mal explorada. Existem hoje os municípios de Guidoval e Marliéria, cujos nomes fazem referência direta ao francês. Infelizmente, há poucos registros de sua influência como urbanista, sendo ainda uma possibilidade de ampliação da pesquisa a procura de novas informações em meio aos descendentes de Marlière. 


\section{Referências bibliográficas}

AGUIAR, José Otávio. Memórias e Histórias de Guido Thomaz Marlière (1808-1836) - A transferência da Corte Portuguesa e a tortuosa trajetória de um Revolucionário Francês no Brasil. 1ª Edição. Campina Grande: EDUFCG, 2008. 433p

ARAÚJO, G. P. Documentos Autobiográficos de Guido Marlière. Revista Chico Boticário. Rio Novo, v. 1, $\mathrm{n}^{\circ}$ 1, p. 15-18. 2004

BARBOSA, Waldemar de Almeida. Dicionário Histórico Geográfico de Minas Gerais. Belo Horizonte: Itatiaia, 1995. 382p.

BURMEISTER, Hermann. Viagem ao Brasil - Através das províncias do Rio de Janeiro e Minas Gerais. Tradução de Manoel Salvaterra e Hubert Schoenfeldt. Belo Horizonte: Editora Itatiaia Ltda; São Paulo: EDUSP, 1980

CARNEIRO, Palmyos Paixão. Os Índios de São Januário do Ubá (1690-1990). Ubá: Gráfica da Escola de Veterinária da UFMG, 1990, 104p.

CARNEIRO, Patrício Aureliano Silva. Conquista e povoamento de uma fronteira: a formação Regional da Zona da Mata no Leste da Capitania de Minas Gerais (1694-1835). Dissertação, Mestrado em Geografia, Universidade Federal de Minas Gerais. Belo Horizonte, 2008. 278p

CUNHA, Manuela Carneiro da. Política indigenista no século XIX. In: História dos índios no Brasil. São Paulo: Companhia das Letras: Secretaria Municipal de Cultura: FAPESP, 1992. p. 133-154

ESPÍNDOLA, Haruf Salmen. Sertão do Rio Doce. Bauru-SP: EDUSC, 2005. 488p.

GAMA, Ignácio Nogueira. Ao Capitão Guido Thomaz Marlière Director das Aldeas do Pomba. Imprensa Oficial e Minas Gerais. Revista do Arquivo Público Mineiro, Belo Horizonte, v. 13, p.8-9.

GIOVANINI, Rafael Rangel. Regiões em movimento. Um olhar sobre a Geografia Histórica do Sul de Minas e da Zona da Mata Mineira (1808-1897). Dissertação, Mestrado em Geografia, Universidade Federal de Minas Gerais. Belo Horizonte, 2006. 204p.

GOOGLE EARTH. Versão 6.0.2. Google Corporation, 2011

HOLANDA, Sérgio Buarque. A herança colonial - sua desagregação. In: (dir.). História Geral da Civilização brasileira. São Paulo: DIFEL, 1965. Tomo II, v. 1: O Brasil monárquico: o processo de emancipação. p. 9-39.

JOSÉ, Oiliam. Marlière, o civilizador. Esboço biográfico. Belo Horizonte: Itatiaia, 1958. 217p.

JOSÉ, Oiliam. Visconde do Rio Branco. Notas para a sua História. Viscode do Rio Branco: Oficinas Gráficas da Papelaria do Império. 1952. 331p.
LANZIERI JUNIOR, Carlile; FRADE, Inácio. Muitas Cataguases - Novos olhares acerca da história regional. Juiz de Fora: Editar, 2006. 160p.

MARGE, Adellunar. Certidão de Idade de Muriaé. Revista Muriaé 150 anos de história 1855-2005. Muriaé p. 5.2005.

MARX, Murillo. Cidade no Brasil: terra de quem? São Paulo: Editora da Universidade de São Paulo, 1991.

MATA, Sérgio da. Chão de Deus - Catolicismo popular espaço e proto-urbanização em Minas Gerais, Brasil. Séculos XVIII-XIX. Berlin: WVB, 2002.

MINAS GERAIS. Programa Integrado de Uso da Tecnologia de Geoprocessamento pelos Órgãos do Estado de Minas Gerais - GeoMINAS. Disponível em <http://www geominas.mg.gov.br/>, acesso em 14/11/2007.

PAIVA, Adriano Toledo "O domínio dos índios": catequese e conquista nos sertões de Rio Pomba (1767-1813). 2009. 291f. Dissertação (Mestrado em História) - Universidade Federal de Minas Gerais, Belo Horizonte, 2009.

PINTO, A. P. Mappa Topographico da Povoação do Presidio. S/L, 1854. Arquivo Público Mineiro, Acervo Cartográfico, PP-012. Disponível em <http:// www.siaapm.cultura.mg.gov.br/ modules/grandes formatos docs/photo. php?lid=220>, acesso em 27/07/2011.

PREFEITURA Municipal de Viçosa. Da Ermida à Urbe. 2010. Disponível em <http://www.vicosa.mg.gov.br/index. php?option $=$ com content\&view $=$ article $\& i d=52 \&$ lte mid $=62>$. Acesso em 12/07/2011.

SILVA, Arthur Vieira de Rezende. O Município de Cataguases - Esboço Histórico - Outubro 1908. Revista do Arquivo Público Mineiro, Belo Horizonte, v. 13, p.641-1028.

SILVA, Gil Bernardino (Org.). Os diários de Langsdorff Campinas, AIEL; Rio de Janeiro, Fiocruz, 1997. vol. I.

SILVA, Tarcísio Glauco. Junta De Civilização e Conquista Dos Índios e Navegação Do Rio Doce: fronteiras, conflitos e apropriação de espaços (1808 - 1822). Revista Ágora, Vitória, n.4, 2006, p. 1-33. Disponível em: <http://www.ufes.br/ppghis/agora/Documentos/R evista_4_PDFs/Tarc\%C3\% ADsio\%20Glauco \% 20 -\%20\%C3\%81gora_4.pdf >

SOARES, Josarlete Magalhães. Das Minas às Gerais: um estudo sobre as origens do processo de formação da rede urbana da Zona da Mata mineira. Dissertação, Mestrado em Arquitetura e Urbanismo, Universidade Federal de Minas Gerais. Belo Horizonte: 2009. $235 p$.

SPIX, J. B. Von, MARTIUS, c. f. p. Von. Viagem pelo Brasil. 1817-1820, 2a Edição. Vol. I. São Paulo: Melhoramentos, 1961

VASCONCELLOS, Diogo. História Media de Minas Gerais. 4 ed. Belo Horizonte: Itatiaia, 1974. 367p. 